
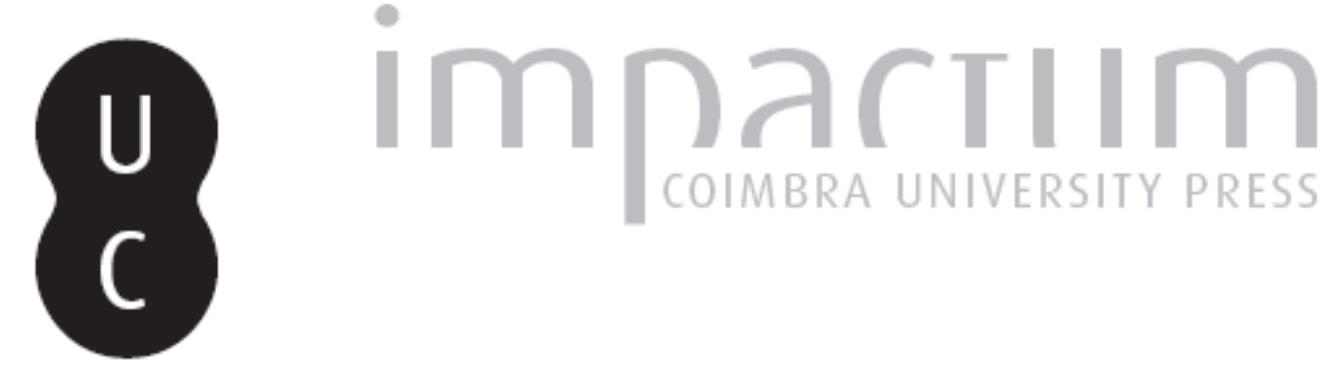

\title{
[Recensão a] VAQUINHAS, Irene - O casino da Figueira. Sua evolução histórica desde o Teatro Circo à actualidade (1884-1978)
}

Autor(es): $\quad$ Alves, Jorge Fernandes

Publicado por: Centro de História da Sociedade e da Cultura

URL

persistente:

URI:http://hdl.handle.net/10316.2/39406

DOI:

DOI:http://dx.doi.org/10.14195/1645-2259_13_24

Accessed : $\quad$ 26-Apr-2023 11:09:21

A navegação consulta e descarregamento dos títulos inseridos nas Bibliotecas Digitais UC Digitalis, UC Pombalina e UC Impactum, pressupõem a aceitação plena e sem reservas dos Termos e Condições de Uso destas Bibliotecas Digitais, disponíveis em https://digitalis.uc.pt/pt-pt/termos.

Conforme exposto nos referidos Termos e Condições de Uso, o descarregamento de títulos de acesso restrito requer uma licença válida de autorização devendo o utilizador aceder ao(s) documento(s) a partir de um endereço de IP da instituição detentora da supramencionada licença.

Ao utilizador é apenas permitido o descarregamento para uso pessoal, pelo que o emprego do(s) título(s) descarregado(s) para outro fim, designadamente comercial, carece de autorização do respetivo autor ou editor da obra.

Na medida em que todas as obras da UC Digitalis se encontram protegidas pelo Código do Direito de Autor e Direitos Conexos e demais legislação aplicável, toda a cópia, parcial ou total, deste documento, nos casos em que é legalmente admitida, deverá conter ou fazer-se acompanhar por este aviso.

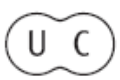



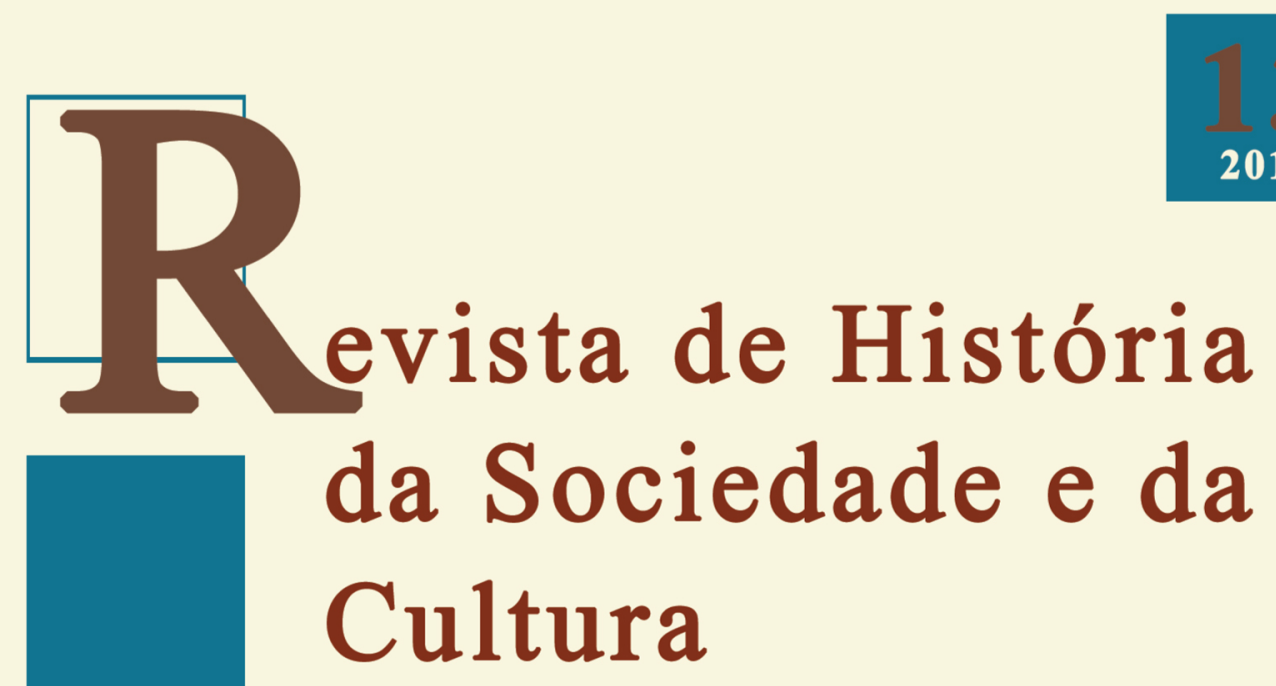

2013

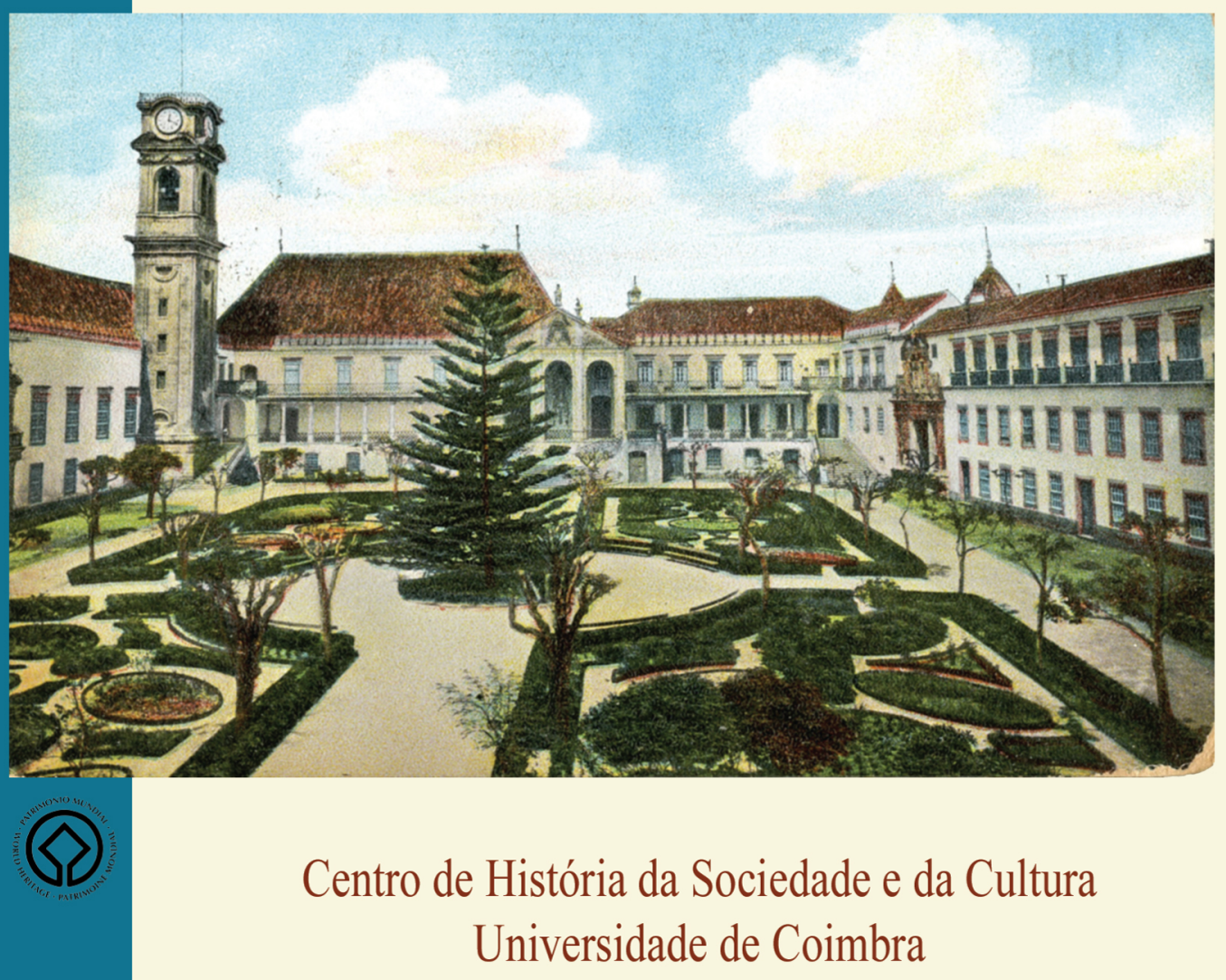

Coimbra 
$\mathrm{Sr}^{a}{ }^{\mathrm{a}} \mathrm{D}$. Olaria digna esposa a seus altos merecimentos, sendo inumerável a sua descendência, que deu a todo o reino, e fora dele» (p. 64); e, em nota, explica Correia Borges que se trata de referências a conhecidas fábricas de faiança de Coimbra: a de Manuel da Costa Brioso, com tendas no Terreiro das Olarias; e a de Domingos Vandelli, fundada em Santa Clara no ano de 1784. Enamorara-se o bule «de sua prima D. Cafeteira, a que havia herdado o dote e importante herança de seu tio Açucareiro de Barros»: «alusão subtil e engraçada», anota o autor, «ao açúcar vindo do Brasil e às fortunas que se fizeram à custa do seu fabrico e tráfico» (p. 65).

Magnífico papel couché, de várias tonalidades, a condizer com as partes em que o livro se divide, recebeu, assim, um texto bem condimentado, requintadamente acompanhado de saborosas ilustrações. A saborear, de facto, como se degusta, em fim de tarde outonal, uma nevada (um «palermo coberto»...), na encosta de Penacova, com o Mondego serpenteando, sorrateiro, a nossos pés...

José d'Encarnação

Universidade de Coimbra

jde@fl.uc.pt

\section{VAQUINHAS, Irene - O casino da Figueira. Sua evolução histórica desde o Teatro Circo à actualidade (1884-1978). Coimbra: Palimage, 2012, 592 pp.}

Irene Vaquinhas, enquanto investigadora, tem-nos habituado a trabalhos inovadores e surpreendentes, constituindo um grato exemplo para a tribo dos historiadores. Continua a ser uma referência a sua seminal tese de doutoramento - Os campos de Coimbra, Montemor-o-Novo e Penacova de 1850 a 1918, a que acrescem trabalhos diversificados na História das Mulheres (a começar pelo acompanhamento científico da edição francesa da obra com esse título), bem como diversos trabalhos e orientações nos domínios da História Económica e Social, da Museologia e do Património Cultural, da História da Vida Privada, da História das Mentalidades, ou, mais recentemente, a história do jogos de fortuna ou azar. Não enunciando 
aqui títulos de todos conhecidos ou facilmente ao alcance de um clique, sublinharei que Irene Vaquinhas apresenta uma extensa e diversificada lista de trabalhos publicados em várias editoras e/ou em várias publicações científicas de prestígio, apresentando um labor intenso e regular ao longo dos anos da sua vida académica. A sua obra, para além de apresentar regulamente propostas inovadoras em campos pouco ou nada explorados, assenta sempre em investigação de profundidade, sustentada em preocupações teóricas e conhecimento /tratamento meticuloso das fontes.

Nesse quadro se inscreve o volume que hoje aqui nos traz, culminando essa escalada de trabalhos sobre a mulher, os costumes, o jogo, a economia. E nesta obra sobre o Casino da Figueira, focando a sua atenção sobre uma instituição muito específica, Irene Vaquinhas concilia sabiamente a escrita da história, a diversos níveis, com a economia, desenvolvendo uma perspetiva institucionalista, para nos fornecer um fresco temporalmente alargado (1884-1978) sobre as configurações e reconfigurações de uma cidade, a Figueira da Foz, que desenvolve uma ancoragem no lazer e no turismo para, a par da indústria, promover um parte substancial do seu crescimento e desenvolvimento.

Assim, revelando-nos o papel do Casino como âncora determinante, a autora mostra-nos também a importância da economia e da sociedade serem consideradas como um todo, como forma de superar as visões das pequenas parcelas isoladas, evidenciando que a economia está ligada à ação política, às mentalidades, à tradição, aos comportamentos e práticas. Nesse quadro, o papel das instituições é sempre relevante, na medida em que nos desvelam formas de comportamento (nos costumes, práticas, modos de pensar), surgindo como elementos fundamentais da cultura, que devem ser observados contudo numa dinâmica de evolução, longe de um equilíbrio estável, que representam interesses de múltiplos grupos sociais que se congregam em favor de reformas a favor do bem comum e não só de ganhos particulares. Estas posições ganharam relevo na transição do século XIX para o XX, procurando superar os limites do marginalismo de então. É nesse âmbito que Thorstein Veblen recupera para a dimensão económica uma visão holística, vislumbrando aquilo que descrevia como a emergência de uma classe ociosa, com necessidade de aparentar fidalguia, através de um consumo conspícuo e da emulação pecuniária, equacionando um quadro em 
que o consumo exprime riqueza, ou seja, poder, prestígio, honra e sucesso numa cultura cada vez mais pecuniária, com as classes trabalhadoras a serem induzidas nos seus comportamentos pelas classes dominantes e ociosas, no seio das quais sublinhava o papel das mulheres como protagonistas desses comportamentos consumistas, enfaixadas em roupas e sapatos, longas unhas e penteados complicados, trajes caros a mostrarem que os maridos são ricos, ou seja, estamos perante uma sociedade de aparência, como assertivamente sublinha Irene Vaquinhas.

O lazer será então legitimado de diversas formas, quer na dimensão económica, superando os discursos centrados apenas no trabalho e na poupança que viam no consumo formas de luxo a que só uma estreita e aristocrática elite poderia assegurar, quer no discurso médico, de índole higienista, que valoriza o corpo e a sua área de ação na promoção/prevenção da saúde, de que o usufruto da praia e/ou das termas se tornam emblemas. Os economistas institucionalistas integram melhor do que ninguém a variável consumo no cerne da economia, vendo os gastos, para muitos supérfluos, como um processo de promoção de trabalho, uma fonte de rendimento e, por esta via ou pela da benemerência, como redistribuição de riqueza. Se o caso do jogo de fortuna ou azar é mais complexo por toda uma tradição proibitiva e pela venalidade dos seus excessos, a verdade é que a viagem e a deslocação que não fosse de trabalho também era, durante muito tempo, mal vista, sendo apenas assumida socialmente como negócio, procura de trabalho (migração) ou de cura ou preocupação científica. Mas o protagonismo de flâneur, esse viajar errante e curioso, que só procura conhecer a sociedade e a natureza, assumido pelos artistas românticos, vai ser transmitido socialmente, com a viagem sem obrigação a integrar as dimensões do lazer e da formação individual, fazendo emergir o turista e, com ele, gradualmente, a indústria do turismo, uma noção inicialmente difusa, mas significando que o turismo tem impacto indireto na economia, para lá dos dispositivos diretamente a ele ligados, sobretudo à medida que a prática do turismo se alarga e se massifica.

Para atrair turismo é preciso, dizem os teóricos, ter "vocação turística", ou seja, equacionar objetivos numa perspetiva de "ganho de atratividade" e de "aumento de competitividade" do destino em relação a outros destinos, o que, para além das características naturais de uma localidade, passa pela oferta, de alojamento, de entretenimento e de lazer. 
Desde o século XIX, pelo menos, que as localidades litorais e particularmente as terras com "foz", ou seja, no enlace de rio e mar, pela sua paisagem diversificada e pelas praias são lugares de atração, de vilegiatura, sustentada nesse potencial hélio-marítimo, feliz expressão recuperada por Irene Vaquinhas de uma tese médica. Mas o desenvolvimento social exigiria mais, com a criação de estruturas e dispositivos tendentes a tornar a localidade acolhedora e a ação rentável.

Foi o que aconteceu na Figueira da Foz, como este livro tão clara e agradavelmente nos revela, numa luta dura e incessante da comunidade, registando uma memória urbana que tem no Casino da Figueira a instituição simbólica e real deste processo histórico de transformar uma cidade piscatória e portuária numa cidade balnear, de lazer, de espetáculos e de jogo, enfim, um polo de atração turística e numa referência nacional em termos de eventos artísticos. Registo feliz numa altura em que o casino assinala já 128 anos.

Como sintetiza a autora a abrir o livro,

são raríssimas as casas de espetáculos, em Portugal, que tenham uma existência tão longa e são em número, ainda mais escasso, as que têm desempenhado um papel de relevo na vida económica, social e cultural das localidades onde se instalaram. Durante largas décadas, o Grande Casino Peninsular foi um dos espaços mais representativos e emblemáticos da Figueira da Foz, senão mesmo o seu símbolo distintivo como local de veraneio e estância balnear. Desde a sua fundação, foi o epicentro de uma intensa vida social, cuja clientela, estritamente selecionada sob o ponto de vista económico e socioprofissional, lhe conferia uma fisionomia elitista, de cunho aristocrático, que a evolução dos tempos tenderia a esbater e a democratizar.

E a autora sublinha que a Figueira e a sua praia vão muito além da sua projeção nacional, sendo indissociáveis de uma intensa procura espanhola que demandava a melhor praia lusitana, como era considerada nos jornais espanhóis. Praia que era complementada pelo Casino, uma instituição que prestava múltiplos serviços de lazer, pois, nela, "o banhista de bom-tom apodera-se das suas salas e salões e é neles que se reúne, conversa, ouve música, assiste a sessões cinematográficas, dança, joga e flirta".

Desafiando Paul Lafargue e o seu direito universal à preguiça, importa sublinhar que a vida de Casino não é para todos, exige comportamentos sociais padronizados: 
Vestir-se para o Casino era uma arte subtil. Não bastava ser elegante, mostrar riqueza, ostentar o luxo, demonstrar que se pertencia às "classes abastadas". Era preciso provar que se tinha um perfeito conhecimento da linguagem da aparência e das conveniências sociais, a qual impunha regras estritas quanto ao modo de trajar, sabendo-o adequar aos tipos de espetáculo ou, inclusive, à forma de estar em sociedade.

A música, os sons, a atmosfera de festa, tudo contribuía para criar a ilusão, esquecendo-se a sobriedade vigente nos locais de trabalho ou de residência... O prazer anicha-se nesses momentos que quebram a vivência quotidiana e que conciliam pudores e imperativos do desejo: esperá-los, prepará-los, vivê-los; depois comentá-los, repensá-los, guardando-os em álbuns de recordações imaginários...

O Grande Casino Peninsular é um pouco de tudo isto. Um espaço cultural, concretizado na realização de concertos, de saraus, de exposições, de carácter recreativo ou beneficente, e um espaço de lazer, consubstanciado nos salões de baile, nas salas de jogo ou na simples observação atenta da clientela que os frequentava.

Mas o Casino torna-se também um polo estruturante do processo de urbanização, ultrapassando em muito a mera atividade de lazer:

A conciliação harmoniosa desta dualidade de funções convertia o Grande Casino Peninsular no polo sensitivo do Bairro Novo, estruturando-se em seu torno os circuitos pedonais, os cafés-casinos com as suas salas de restaurante e de jogo e os seus agrupamentos de jazz-band, que anualmente, pela época balnear, conferiam à pacata e discreta cidade da Figueira da Foz a animação e o bulício de uma qualquer cosmopolita cidade de banhos...

A história do Casino Peninsular não se pode, pois, confinar aos estreitos limites da Rua dos Casinos ou à ociosidade dourada das salas de jogo, nem tão pouco pode ser unicamente encarada como um mero estudo de empresa, por mais vicissitudes que esta tenha passado, desde a sua fundação.

Ultrapassando as limitações que adviriam de uma mera história de empresa, Irene Vaquinhas oferece-nos várias histórias num só volume, qual matrioska russa: a história do Casino é uma contributo para a história da cidade num tempo definido, mas é também um contributo para a história do jogo, para a história social e das elites, para história da cultura e dos espetáculos, para a história das relações entre poder local e poder central. Tudo isso nos surge numa narrativa sabiamente urdida, num esforço 
desmesurado pela busca de informação, com uma bibliografia extensíssima e um manancial de fontes inerentes à reconstituição histórica, em que avultam o fundo documental camarário da Figueira da Foz, que a autora considera extraordinariamente rico e bem organizado, e a imprensa periódica figueirense, com particular destaque para os jornais de maior longevidade: a Gazeta da Figueira, O Figueirense, a Voz da Justiça e o Mar Alto.

Nesta digressão, para ganharmos fôlego, somos convidados a ler uma narrativa organizada em nove capítulos, para além da introdução, conclusão, fontes e bibliografia e anexos, incluindo um caderno de belíssimas imagens. Um primeiro capítulo mostra-nos a afirmação da praia, os primórdios da vilegiatura marítima e papel de praia peninsular da Figueira da Foz, nesse processo de alteração das conceções de lazer. Não fugindo ao campo das rivalidades locais, entramos depois na criação do Teatro-Circo Saraiva de Carvalho e sua evolução até à sua definição como Casino Peninsular (1884-1895), à sua gradual distinção social em relação a outros casinos, e à sua capacidade de sobreviver face às proibições de jogo que ocorreram com Hintz Ribeiro e às indefinições que seguiram mesmo na República, não obstante o acalorado debate que se viveu no parlamento de então (1912). Quadro histórico em que se afirmou a construção de uma reputação: o Casino Peninsular como uma casa de recreio familiar, com programações diversificadas.

Com o decreto $n^{\circ} 14643$, de 3 de dezembro de 1927, ultrapassaram-se as discussões parlamentares sobre o jogo, atividade central de um casino, e que sempre campeara nas praias, nas termas e nas cidades: nessa altura, o Estado regulamenta a atividade e tira vantagens financeiras. Figueira da Foz é uma das poucas localidades em que o jogo é autorizado e concessionado.

Dos primeiros anos da concessão do jogo (1928-1937), surgiria o Grande Casino Peninsular da Figueira da Foz, com contrato de adjudicação do exclusivo dos jogos de fortuna ou azar e a constituição da sociedade do Grande Casino Peninsular da Figueira da Foz SARL: tudo acabará por confluir no grupo CUF, através da casa bancária José Henriques Totta, Lda. A questão do jogo debate-se de novo, nessa altura, no seio do poder e também da empresa, dada a sua pouca rentabilidade em tempo de crise, mas a perda da concessão resulta num casino "mais chic, mais distinto, mais civilizado e decente, com "programas oficiais das festas", a que a 
acrescem os concertos e as "variedades", as festas temáticas, o cinema sonoro, com o "reinado das fitas americanas".

Não tendo a empresa construído o hotel previsto no contrato de concessão (decreto $n^{\circ} 36890$, de 29 de maio de 1948), este foi dado como extinto, com a gestão a ser assumida pela Câmara Municipal. A gestão autárquica da exploração do jogo em tempo de guerra (1938-1948), a que não faltaram os refugiados alemães e os volframistas, ajuda a legitimar socialmente o jogo através da aplicação dos seus resultados e dos derivados de espetáculos à benemerência de entidades locais, ainda que esta exploração seja irregular.

O contributo do Grande Casino Peninsular para o aumento do fluxo turístico da cidade, atraindo visitantes e ativando sectores económicos, foi reconhecido pelo comércio local, como relata a autora, quando da homenagem de Dezembro de 1948, à Direção do casino, presidido por Álvaro Malafaia, ao tempo presidente da Câmara Municipal, sublinhando-se então a presença de "filhos da terra", na direção da então criada Sociedade Figueira Praia, que aproximou a empresa dos figueirenses, de novo se "encarnando a esperança de uma verdadeira melhoria para toda a cidade, dado o lugar central que o casino ocupava na economia urbana".

Finalmente, a 28 de Junho de 1953, tal como impunha o Decreto-lei $n^{\circ} 36890$, foi inaugurado, com pompa e circunstância, o Grande-Hotel da Figueira, tendo estado presente na cerimónia, o Ministro do Interior, Engenheiro Cancela de Abreu.

A inauguração do Grande Hotel da Figueira significou um importante investimento na área do turismo. Tanto o Grande Hotel da Figueira como a Piscina-Praia vieram enriquecer a oferta turística e modernizar o tecido urbano, tendo conseguido prolongar os seus efeitos por longas décadas, com consequências duradouras e muito significativas até à atualidade, refere a autora. Os dois empreendimentos passaram a constituir infraestruturas fundamentais do aparelho económico e de animação da cidade, adquirindo grande significado na capacidade de captação de turistas e de atração dos mais diversos acontecimentos.

A Comissão Municipal de Turismo enquadrará o Grande Hotel e a Piscina-Praia na malha dos seus interesses de um modo especial a partir de 1958. As campanhas publicitárias relançam a nova imagem da cidade, projetando o Grande Casino Peninsular e o Grande Hotel da Figueira como 
"dois elementos fundamentais da Figueira da Foz" e exibindo-os como "cartazes de efeito seguro no espírito do visitante". A exemplo do sucedido na década anterior com o Grande Casino Peninsular, a Comissão Municipal de Turismo passou a realizar muitas das atividades festivas nos novos espaços recém-inaugurados.

$\mathrm{Na}$ assertivamente designada "era do "capitalismo sem complexos", a Sociedade Figueira Praia revela expansão, no período 1951-1976, através de uma nova unidade hoteleira e a aquisição da propriedade denominada "Sotto Mayor", transação formalizada em 1967, acompanhando as mudanças económicas e sociais e a evolução da conjuntura política. Veio o tempo das atividades culturais e recreativas, as festas "com ordem e animação" (1948-1958): "exposições, espetáculos e provas desportivas”. E, na sequência, chegou o tempo dos Festivais da Canção Portuguesa (1961-1973), com a televisão, introduzida em Portugal em 1957. A partir de 1961, os festivais da canção passam a realizar-se na Figueira da Foz, no Grande Casino Peninsular. Um período de grande projeção, quer pelas transmissões, quer pela visita de grandes artistas internacionais, permitindo projetar e consolidar a imagem da Figueira da Foz como uma estância balnear cosmopolita e popular: a "cidade-praia", ação decalcada de outras estâncias europeias que se "lançaram" com a realização dos respetivos festivais (San Remo, em Itália, Benidorm e Palma de Maiorca, em Espanha), procurando-se promover a Figueira da Foz como destino turístico por excelência.

O Festival da Canção começou, pois, a integrar o "programa turístico da cidade" a partir de 1961, embora nem todos os festivais aqui realizados tenham sido transmitidos pela televisão, como aconteceu com o de 1964, por "dificuldades técnicas", como se esclarece nas atas camarárias, mas que, segundo a autora, se afigura ter sido, acima de tudo, uma razão de problemas financeiros. Irene Vaquinhas sublinha o facto de os festivais proporcionarem uma abertura ao estrangeiro que vem reforçar momentos de mudança. Em Agosto de 1968, atua no casino Juan Manuel Serrat, um nome da "nova canção catalã" que chega à Figueira precedido de uma grande polémica: tendo sido selecionado para representar Espanha no Festival da Eurovisão de 1968, recusara-se a fazê-lo, por não lhe ter sido permitido cantar em catalão. Cerca de um ano depois, em 1969, Zeca Afonso, Adriano Correia de Oliveira, Manuel Freire, Rui Pato, Fátima Morais, entre outros 
artistas de uma nova geração de cantores, representantes das "modernas expressões da nossa música", atuaram no casino, quer em espetáculos a favor da Santa Casa da Misericórdia da Figueira, quer no $1^{\circ}$ Festival da Música Popular Portuguesa

Um terceira parte da obra, é dedicada ao edifício, aos seus espaços, programas decorativos, adaptações e readaptações. E a um capítulo final, intitulado "Amigos de estimação: a colónia balnear espanhola", no qual se evoca "Agosto, o mês das espanholas, o mês da alegria restolhenta e contagiosa, o mês que se vive sem se saber como, num estonteamento e numa vertigem", conforme transcrição do jornal O Figueirense, de 25 de setembro de 1935. São muitas os testemunhos na imprensa de manifestações de apreço da comunidade do país vizinho pela "mais linda praia portuguesa", com o Casino a organizar Las noches del Casino Peninsular.

Enfim, o Casino da Figueira, nas suas diversas configurações e fórmulas societárias que a administraram, foi um elemento central da atividade económica e social. A autora procurou, segundo afirma, identificar o contributo específico e singular de cada uma das empresas que a geriram e de captar a sua identidade como casino e casa de espetáculos na cidade da Figueira da Foz.

Eis um livro denso de informação, assente em escolhas criteriosas, de leitura agradável, com objetivos claramente alcançados, a ler com prazer e proveito não só dos figueirenses, mas sim de quantos se interessam pelo desenvolvimento local e sua explicação histórica, pela história das mentalidades e da cultura, pela história económica e social, pela história global.

Jorge Fernandes Alves

CITCEM/FLUP

jorge.falves@gmail.com

BOTELHO, Maria Leonor - A Historiografia da Arquitectura da Época Românica em Portugal (1870-2010), Lisboa: Fundação Calouste Gulbenkian e Fundação para a Ciência e a Tecnologia, 2013 (866 páginas).

Em Maio de 2013, no âmbito da colecção "Textos universitários de Ciências Sociais e Humanas", a Fundação Calouste Gulbenkian e a Fundação 